\title{
Recent treatment advances and novel therapeutic approaches in epilepsy
}

\author{
Enrique Serrano and Andres M. Kanner*
}

\author{
Address: Department of Neurology, University of Miami, Miller School of Medicine, 1120 NW 14th Street, Miami, FL 33136, USA \\ *Corresponding author: Andres M. Kanner (a.kanner@med.miami.edu) \\ Fl000Prime Reports 2015, 7:61 (doi:10.12703/P7-6I) \\ All FI000Prime Reports articles are distributed under the terms of the Creative Commons Attribution-Non Commercial License \\ (http://creativecommons.org/licenses/by-nc/3.0/legalcode), which permits non-commercial use, distribution, and reproduction in any medium, \\ provided the original work is properly cited. \\ The electronic version of this article is the complete one and can be found at: http://f $1000 . c o m / p r i m e /$ reports/m/7/6 I
}

\begin{abstract}
The purpose of this article is to review recent advances in the treatment of epilepsy. It includes five antiepileptic drugs that have been recently added to the pharmacologic armamentarium and surgical techniques that have been developed in the last few years. Finally, we review ongoing research that may have a potential role in future treatments of epilepsy.
\end{abstract}

\section{Introduction}

Epilepsy is a chronic disorder affecting 50 million people worldwide [1-3]. It is characterized by recurrent seizures due to abnormal excessive and synchronous neuronal activity in the brain [4]. The International League Against Epilepsy [ILAE] defines epilepsy as "a disease characterized by an enduring predisposition to generate epileptic seizures and by the neurobiological, cognitive, psychological, and social consequences of this condition". Thus, the impact of epilepsy is not only limited to the actual seizures but also inclusive of the effects of antiepileptic drugs (AEDs) and other treatments and the psychosocial, psychiatric, cognitive and medical comorbidities associated with the seizure disorder [4].

\section{Novel drug treatments for epilepsy}

Since the 1990s, 15 new AEDs have been added to the pharmacologic armamentarium of epilepsy. These have been separated into second- and third-generation AEDs; the former include felbamate, gabapentin, lamotrigine, levetiracetam, oxcarbazepine, pregabalin, tiagabine, topiramate, vigabatrin, and zonisamide. Third-generation AEDs introduced in the last 5 years include lacosamide, (LCM), rufinamide (RFN), ezogabine (EZG), eslicarbazepine (ESL), and perampanel (PER). These AEDs will be reviewed in greater detail below:

\section{Lacosamide}

LCM is an AED that enhances the slow inactivated state of voltage-gated sodium channels (VGSCs) [5], making the number of VGSCs less available for activation without affecting the fast inactivated state as in the first- and second-generation sodium channel blockers (phenytoin, carbamazepine, lamotrigine, etc.). This inactivation prevents channel opening, helping stop the action potential in depolarized neurons in the epileptic focus. LCM is approved for focal epilepsy, and studies to establish its safety and efficacy in idiopathic generalized epilepsy are on the way. It has a favorable pharmacokinetic profile, with low binding to albumin and no pharmacokinetic interaction with other AEDs or other medications, but may have a pharmacodynamic interaction with other sodium channel blockers when used at high doses, resulting in cerebellar adverse events. In addition to its oral formulation, it is available as an intravenous formulation, which has led to its use in the management of status epilepticus (SE) in many centers.

In a multicenter, double-blind, placebo-controlled, randomized trial, LCM was found to be effective at doses of 200 and $400 \mathrm{mg} /$ day as add-on therapy for focal epilepsy [6]. In another double-blind, multicenter, randomized study, a $600 \mathrm{mg} /$ day dose was found to be more effective 
than a $400 \mathrm{mg} /$ day dose in reducing secondarily generalized seizures. However, the $400 \mathrm{mg} /$ day dose was associated with fewer adverse effects [7].

LCM recently received monotherapy approval by the U.S. Food and Drug Administration (FDA) in 2014 for focal epilepsy. Thus, LCM can now be prescribed as initial monotherapy in patients with newly diagnosed epilepsy or converted to monotherapy, which will yield fewer side effects and better compliance. In addition, the FDA approved a loading dose (oral or injection) of $200 \mathrm{mg} /$ day followed 12 hours later by a $100 \mathrm{mg}$ twice-aday maintenance dose.

As stated above, LCM has been used with increasing frequency in the management of SE. In a recent presentation at the annual meeting of the American Epilepsy Society in December 2014, Ramsey et al. suggested the use of loading doses targeting a serum concentration of $12 \mathrm{mg} / \mathrm{l}$. Careful monitoring of PR interval was recommended, however [8].

Common side effects include dizziness, ataxia, double vision, nystagmus, and nausea. LCM should be used with caution in patients who have known cardiac conduction problems, such as first-degree atrioventricular (AV) block, second-degree or higher AV block and sick sinus syndrome without pacemaker, or who are on concomitant medications that prolong PR interval.

\section{Rufinamide}

RFN is a structurally unique triazole derivative that prolongs the inactive state of sodium channels and slows sodium channel recovery. Although it has been shown to have efficacy in focal epilepsy, it is used primarily in the treatment of drop attacks in Lennox Gastaut Syndrome (LGS). RFN is well tolerated with few cognitive and psychiatric adverse events. It is metabolized in the liver and, consequently, its clearance is increased in the presence of enzyme-inducing AEDs (e.g. carbamazepine, phenobarbital, phenytoin, and primidone), limiting its efficacy, while valproate inhibits its metabolism, yielding an increase in its serum concentrations.

Class I evidence shows RFN to be superior to placebo as add-on therapy in focal epilepsy, with respect to reduction of median seizure frequency and to responder rate $[9,10]$ at doses of $3200 \mathrm{mg} /$ day, with $400 \mathrm{mg} /$ day being the lowest effective dose [9]. However, the magnitude of the efficacy is modest, at best.

On the other hand, the efficacy and tolerability of RFN in LGS were demonstrated in one multicenter, randomized, double-blind, placebo-controlled trial conducted in
138 patients with LGS (age range 4 to 30 years old) [11]. Patients randomly assigned to RFN experienced a significantly greater median percentage reduction in total seizure frequency $(32.7 \%$ vs. $11.7 \%)$ and in the frequency of drop attacks (42.5\% median percentage reduction vs. $1.4 \%$ increase on placebo) and significantly greater improvement in seizure severity and responder rate for total seizures.

RFN was found to be well tolerated; the most frequent adverse events in these studies included dizziness, fatigue, nausea, somnolence, diplopia, confusion, ataxia, and impaired concentration. It should be used with caution when given with other medications that shorten the QT interval. In addition, AED hypersensitivity syndrome has been associated with RFN therapy.

\section{Ezogabine}

EZG is a novel AED that is used as add-on treatment for treatment-resistant focal epilepsy. It has a novel mechanism of action mediated by activating voltage-gated potassium channels, causing hyperpolarization of the membrane potential and stabilizing the resting membrane potential. It has limited pharmacokinetic drug interactions because it is not metabolized through the cytochrome P450 system and is not highly protein bound.

Class II evidence shows that EZG doses of 600, 900, and $1200 \mathrm{mg} /$ day were superior to placebo with respect to median percentage seizure reduction and responder rates. However, a high proportion of treatment discontinuation was observed in these studies because of adverse events.

The most frequent adverse events included dizziness, somnolence, fatigue, speech disorder and confusion [12-14]. In addition, EZG may cause urinary retention because of its effect on potassium channels in the urothelium of the bladder. Furthermore, the FDA issued a warning indicating that EZG can cause a blue discoloration in the skin and retina [15]. The clinical significance of the retinal discoloration is yet to be established, but the potential for a retinopathy cannot be excluded. Therefore, a risk-benefit assessment should be performed before starting this medication.

\section{Eslicarbazepine}

ESL acetate is a VGSC blocker that is chemically related to carbamazepine and oxcarbazepine [16]. A chemical variation at the 10,11 position, however, allows differences in metabolism between carbamazepine and ESL, limiting the production of the toxic carbamazepine-10,11 epoxide $[17,18]$. Furthermore, ESL acetate was developed to overcome the unnecessary production of enantiomers, 
allowing for a lower drug interaction potential. Oxcarbazepine is a prodrug that is metabolized into both the $\mathrm{S}$ - and R- enantiomers of licarbazepine, while ESL is metabolized to the S- enantiomer of licarbazepine [18]. This conversion of ESL to S-licarbazepine is believed to be the reason for fewer adverse neurological effects [19]. In addition, with its simple titration schedule and oncedaily dosing, ESL allows increased drug compliance.

Class I evidence demonstrates the efficacy of this AED as adjunctive therapy in treatment-resistant focal epilepsy at 800 and $1200 \mathrm{mg} /$ day doses given once/day [20]. A 1 -year open-label extension study of patients who completed the above double-blind, randomized, placebo-controlled study also showed long-term benefits including improvement of quality of life and depressive symptoms [21]. Treatment-related adverse events are generally dose dependent and the most frequent ones include dizziness, headache, diplopia, somnolence, nausea, emesis, and poor coordination. Patients should be monitored for serious rash and hyponatremia.

\section{Perampanel}

PER is an AED that acts as an antagonist of the $\alpha$-amino3-hydroxy-5-methyl-4-isoxazole propionic acid (AMPA) receptor of glutamate, which is the primary excitatory neurotransmitter. PER was approved as an add-on therapy for drug-resistant focal epilepsy. Although it is neither a P450 enzyme inducer nor inhibitor, its clearance can be accelerated with enzyme-inducing AEDs. Its long half-life allows once-a-day dosing, facilitating compliance.

Class I evidence shows the efficacy and tolerability of PER at doses of 8 and $12 \mathrm{mg} /$ day when compared to placebo. Both doses were found to be superior to placebo with respect to median percent seizure reduction $[22,23]$, yet PER has a boxed warning for serious psychiatric and behavioral reactions, such as aggression, hostility, irritability, anger, and homicidal ideation, and threats from patients randomly assigned to PER have been reported. Accordingly, it is essential to identify patients at risk for psychiatric comorbidities (e.g. those with a prior and/or family psychiatric history).

For these newer AEDs, starting at a low dose and following a slow titration may diminish the risk of adverse events. A careful risk-benefit assessment should be performed before starting some of these AEDs, such as EZG and PER. There are several potential benefits of using these new AEDs over the current or earlier drug classes. For example, LCS has no reported drug interactions with AEDs and other medications and can be loaded intravenously in patients with frequent seizures, yielding the rapid achievement of optimal serum concentrations. ESL is structurally modified to minimize side effects and has a longer half-life, allowing for once-daily dosing, which will improve compliance. Several of the newer AEDs, including PER and EZG, have mechanisms of actions that are not shared with any of the other available AEDs and can be used in combination with other AEDs, potentially increasing their efficacy.

\section{Novel non-drug treatments for epilepsy Laser thermal ablation}

Magnetic resonance imaging (MRI)-guided laser thermal ablation for epilepsy is a new procedure performed in patients with treatment-resistant focal epilepsy with MRI-visible lesions, such as mesial temporal sclerosis and focal dysplasias. Its aim is to "burn" these structures. Unlike resective surgery, such as antero-temporal lobectomies, laser ablation can be performed via a small burr hole in the skull through which a laser fiber is introduced and advanced with MRI guidance until it reaches the target structures. The inpatient stay ranges between 1 and 2 days in general, and the recovery times are short [24].

In a study comparing pre- and post-treatment neuropsychological data in 17 people with temporal lobe epilepsy (TLE), a better outcome on episodic memory measures was demonstrated in patients treated with MRI-guided laser thermal ablation at 6 months than in patients who underwent an antero-temporal lobectomy [24].

A multicenter study reported at the 2013 American Epilepsy Society meeting suggested that postsurgical seizure freedom rates in patients who underwent MRIguided laser ablation of mesial temporal structures approached those of antero-temporal lobectomies: $58 \%$ at 6 months and $50 \%$ at 1 year [25].

\section{Brain Stimulation}

The RNS system (Mountain View, California) is a novel treatment option that was approved by the FDA in 2013 for patients with treatment-resistant epilepsy [26]. It was developed as a palliative treatment for patients in whom the epileptogenic area is in eloquent cortex or those with two independent foci. Its efficacy was demonstrated in one class I study [27]. The RNS system delivers electrical stimulation only when triggered by epileptic activity detected by a computer chip pre-programmed to identify it. The neurostimulator is placed in a compartment carved within the skull and is connected to one or two intracranial electrodes (depth electrodes and/or subdural strips) that target the presumed epileptogenic areas [27]. This device has been well tolerated and was not found to cause any adverse psychiatric or cognitive events. 


\section{Where are we heading in the treatment of epilepsy? \\ Epileptogenesis}

Despite the relatively large number of AEDs available in the treatment of epilepsy, it has been estimated that up to $30 \%$ of patients are resistant to the currently available pharmacotherapy [2], while a percentage of these patients may not be candidates for epilepsy surgery. Therefore, therapeutic interventions for epilepsies not amenable to the currently available treatments continue to be pursued with a major emphasis on the development of antiepileptogenic agents as well as drugs that may modify the epileptic process once the disease has started to prevent treatment-resistant epilepsy or the development of associated cognitive and/or psychiatric comorbidities [28,29].

Epileptogenesis is an ongoing process by which an insult to the central nervous system causes a normal brain to be capable of generating spontaneous and recurrent seizures [30,31]. Epileptogenicity also encompasses the changes that contribute to disease progression as well as the cognitive and behavioral consequences after the onset of epilepsy [32].

SE, stroke, brain tumors, prolonged febrile seizures, encephalitis, genetic malformations, and traumatic brain injury (TBI) are common conditions that have been associated with the development of epileptogenesis [31,33]. It may take months or years for spontaneous recurrent seizures to develop following a brain insult, and during that time there may be functional and/or structural alterations such as axonal and dendritic sprouting, inflammation, neuronal loss, gliosis, alterations in receptor and ion channel function, and hyperexcitability of neurons. The period of time that begins during or after the brain insult and ends at the time of the first seizure is known as the silent or latent period [31].

The latent period after brain insult may offer a window of opportunity in which treatment may stop the epileptogenic process or modify the natural course of the disease [33], minimizing the development of treatment-resistant epilepsy and of comorbidities [29,32].

\section{Antiepileptogenesis in TBI and SE}

Several clinical trials have been carried out to evaluate the prophylactic effects of conventional AEDs on the long-term effects of TBI [34]. These trials have shown a failure to prevent epileptogenesis with the administration of phenytoin, phenobarbital, carbamazepine, or valproate [34]. Several experimental studies have also seen a lack of antiepileptogenic effect in SE rat models of TLE [31]. There is minimal evidence that the existing AEDs prevent epilepsy or alter the natural history of the disease [29,33].

\section{The role of $\mathrm{AEDs}$ in disease modification}

Some AEDs may have a role in modifying the disease process once epilepsy has started. For instance, treating certain idiopathic generalized epilepsies such as juvenile absence epilepsy may prevent the occurrence of other seizure types. Furthermore, early and successful treatment of West syndrome with vigabatrin appears to yield a better cognitive outcome in babies affected with this seizure disorder [28].

\section{Novel approaches for antiepileptogenesis The mTOR signaling pathway}

Mammalian target of rapamycin (mTOR) is a serine/ threonine protein kinase that regulates cell growth, differentiation, protein synthesis, and transcription [36]. mTOR signaling is dysregulated in a variety of human disorders including cancer, diabetes and epilepsy and may be responsible for epileptogenesis by enhancing neuronal excitability $[37,38]$. Hyperactivation of mTOR signaling in epilepsy makes it a potential mechanism in the disease's pathogenesis as well as a possible target for therapeutic intervention [39].

Dysfunction of the mTOR pathway has been implicated in tuberous sclerosis complex (TSC), which is a genetic disorder related to brain tubers associated with the development of infantile spasms, focal and generalized seizures and mental retardation often linked with autism [40]. It is caused by mutations in the genes encoding hamartin (TSC1) and tuberin (TSC2) that are involved in the regulation of cell proliferation and differentiation and inhibit the mTOR pathway [41]. Thus, these mutations can give rise to hyperactivation of the mTOR pathway [42].

Animal models have shown that mTOR inhibitors have antiepileptogenic properties by preventing the development of epilepsy when initiated prior to the onset of seizures or decreasing their occurrence when started after their onset [43].

Rapamycin is an mTOR inhibitor that exhibits immunosuppressive activity by blocking the G1 to S phase of the cell proliferation cycle in T-lymphocytes [44]. Furthermore, animal data have shown that rapamycin attenuates the development of epilepsy [35]. Rapamycin has also been found to display anticancer properties and ameliorate the progression of renal failure in animal models of chronic kidney disease [45]. 
An animal study by Zeng et al. using a rat model of TLE after SE showed that rapamycin administered after SE was able to reduce mossy fiber sprouting and the development of spontaneous seizures [35]. In fact, mossy fiber sprouting has been found to play an important pathogenic role in epileptogenesis. These data suggested that mTOR inhibitors could have antiepileptogenic properties. At this time, however, there are no human clinical trials of rapamycin for TLE.

In epileptic patients treated with everolimus for subependymal giant cell astrocytoma (SEGA) in TSC, Moavero et al. found that seizures appeared to decrease in frequency and in severity [41]. However, its discontinuation was followed by seizure recurrence with the same frequency. The authors emphasized that caution should be used when everolimus is used with AEDs because of their potential pharmacokinetic and pharmacodynamic interactions [41].

\section{Brain inflammation}

Brain inflammation may play an important role in the epileptogenic process [46]. Inflammation normally protects tissues from infections or injuries, but a dysregulated inflammatory response can alter normal cell function, cause cell death, and disrupt the blood-brain barrier (BBB) [47]. A disruption of the BBB as seen in brain trauma and tumors can lead to seizures and treatment-resistant epilepsy [48].

A lower seizure threshold in brain inflammation can result in increased neuronal excitability, modification of membrane ion channels, disruption of neurotransmitter uptake and release, and altered BBB permeability [46,49-52]. Signs of chronic inflammation including leukocyte infiltration, cytokine overexpression, and reactive gliosis have been found in resected brain tissue from humans with refractory focal epilepsy $[53,54]$.

Anti-inflammatory medications, such as corticosteroids and adrenocorticotropic hormone (ACTH), have been used in pediatric treatment-resistant epilepsies, providing evidence that epilepsy may have an immune inflammatory component.

Cytokines and related inflammatory mediators are rapidly synthesized during seizures [47]. Therefore, a novel therapeutic approach for epilepsy is to target brain inflammation in treatment-resistant epilepsy. Interleukin 1-beta (IL-1 $\beta$ ), transforming growth factor-beta-1, and cyclooxygenase-2 (COX-2) are three inflammatory mediators that may have roles in epileptogenesis and may have proconvulsant effects $[47,51]$.
Experimental studies have demonstrated the anticonvulsant activity of specific anti-inflammatory drugs, such as COX-2 inhibitors and inhibitors of IL-1 $\beta$-converting enzyme (ICE)/caspase- 1 and antagonists of IL-1 $\beta$ receptors [55-58]. These drugs may have therapeutic potential in epilepsies associated with proinflammatory processes in the brain.

\section{COX-2 inhibitors as potential therapeutics in epilepsy}

Studies have shown that brain COXs, the rate-limiting enzymes which catalyze the metabolism of arachidonic acid to prostaglandins, are upregulated and induced by seizures [57].

Celecoxib is a non-steroidal anti-inflammatory drug (NSAID) that has been tested in epileptogenesis models. Using lithium-pilocarpine, Jung and colleagues [59] induced SE in adult rats and commenced celecoxib 1 day after onset of SE, and then continued to administer the treatment for 42 days. Treatment with celecoxib showed a decrease in seizure frequency and duration but did not reduce the number of rats that developed epilepsy. In addition, it was shown that hippocampal neurodegeneration and microglial activation was reduced by celecoxib, and inhibited the generation of both ectopic granule cells in the hilus and new glia in CA1 [59].

Parecoxib, another NSAID, belongs to the second generation of selective PTGS2 inhibitors. Polascheck and co-workers [60] administered parecoxib for 18 days after pilocarpine-induced SE. There were no observations of reductions in the occurrence of epilepsy or the duration or frequency of seizures. However, when compared with vehicle alone parecoxib did slightly reduced the behavioral severity of seizures [60].

It has also been shown that COX-2 inhibitors may improve pharmacotherapy in treatment-resistant epilepsy by decreasing the upregulation of P-glycoprotein, which limits penetration of AEDs in the BBB [61]. P-glycoproteins are upregulated during seizures, serving as a mechanism of drug resistance by limiting AED BBB penetrance and AED efficacy [61].

\section{ICE/caspase-I inhibitors and IL-I $\beta$ receptor antagonists as potential therapeutics in epilepsy}

ICE/caspase- 1 is an intracellular protease that cleaves the precursors of IL-1 $\beta$ into active cytokines. There is evidence of increased levels of IL-1 $\beta$ and IL-1R1 and increased ICE/ caspase- 1 activation in surgically resected epileptogenic tissue from patients with treatment-resistant TLE [62]. As an inflammatory enzyme, caspase- 1 is involved in the 
production of IL-1r and is linked to a wide range of immune and inflammatory responses.

Induction of ICE/caspase- 1 and activation of IL-1teIL-1 receptor type 1 axis have been seen in human epilepsies and can contribute to experimentally induced acute seizures. VX-765, a selective inhibitor of ICE, has been shown to inhibit acute partial seizures in preclinical models and has shown activity in preclinical models of chronic partial epilepsy that do not respond to currently available medicines for epilepsy [63]. An investigation of its safety and efficacy in humans with focal epilepsy has been started, but no published data are yet available.

\section{Neurodegeneration}

Chronic TLE is associated with hippocampal sclerosis, which is an expression of a neuropathologic degenerative process $[64,65]$. The prevention of programmed cell death causing neurodegeneration may offer new drug therapies in the treatment of TLE. Caspase- 2 is an enzyme involved in inflammation as well as programmed cell death (apoptosis). To study the evolution of altered caspase-2 expression during epileptogenicity and after the onset of epilepsy, Narkilahti and colleagues analyzed the expression of caspase- 2 in surgically resected hippocampal tissues from patients with treatment-resistant TLE and in rat hippocampus after SE [66]. Caspase-2 expression was increased in hippocampal neurons of patients with TLE. Their data suggested that caspase-2-mediated programmed cell death participates in the seizure-induced degenerative process in experimental and human TLE [66].

\section{Neurosteroids}

Neurosteroids and steroid hormones are known to have anticonvulsant and proconvulsant properties. Progesterone and estrogen are hormones synthesized in the ovaries and are released cyclically during menstruation. It is known that progesterone has anticonvulsant properties and that estrogen has proconvulsant properties. A rise in estrogen before ovulation and a decrease in progesterone before menstrual bleeding can make women with epilepsy more susceptible to seizures.

Progesterone is converted to allopregnanolone, a neurosteroid with anticonvulsant properties, by 5-alphareductase [67]. Allopregnanolone binds to GABA-A receptors, enhancing GABA-A receptor-mediated inhibition by stimulating inward flow of chloride, causing membrane hyperpolarization [68-74]. It is known that the binding site of allopregnanolone is not the same as that of benzodiazepines or barbiturates and that neurosteroids may play a role in the treatment of seizures that are resistant to benzodiazepine therapy.
The role of neurosteroids in epileptogenesis has been studied in mouse models, providing evidence that neurosteroids can attenuate the development of spontaneous recurrent seizures in kindling models. A study by Reddy and colleagues showed that kindled seizure activity caused by daily hippocampal stimulation was suppressed with a 2-week treatment of progesterone [75]. Reddy and Ramanathan [76] also showed that progesterone's inhibition of epileptogenesis was blocked by finasteride, a 5-alpha-reductase inhibitor, by reducing the synthesis of neurosteroid.

Ganaxolone, which is being developed for clinical use, is a neurosteroid analog to allopregnanolone and a GABA-A receptor modulator with anticonvulsant properties. A randomized, double-blind, placebo-controlled phase II trial examined the safety and efficacy of ganaxolone $(1500 \mathrm{mg} /$ day $)$ as add-on therapy in 147 adults (100 females and 47 males) with focal epilepsy. This study found that ganaxolone reduced mean weekly seizure frequency by $18 \%$ compared with a $2 \%$ increase for placebo over a 10-week treatment period $(P=0.014)$. Responder rates were $26 \%$ for the ganaxolone group versus $13 \%$ for placebo $(P=0.057)$; this difference did not reach statistical significance. It was noted in this study that the discontinuation rate due to adverse events was $7 \%$ for ganaxolone and $6 \%$ for placebo. No safety concerns were identified during extended treatment with ganaxolone for up to 104 weeks [77]. An ongoing phase III double-blind, placebo-controlled study designed to evaluate its safety and efficacy at doses of 1200 and $1800 \mathrm{mg} /$ day in adults with focal epilepsy is underway. This study, unlike the phase II trial, will help determine if there is a greater response to the higher doses.

\section{New drugs in the pipeline for epilepsy}

The following are new drugs in the pipeline for epilepsy: BGG492 (Novartis), a competitive AMPA/kainate receptor antagonist; Brivaracetam (UCB), a novel high-affinity SV2A ligand; CPP-115 (Catalyst), a GABA transaminase inhibitor (vigabatrin derived); ICA-105665 (Pfizer), a highly selective opener of neuronal Kv7 (KCNQ) potassium channels; T2000 (Taro), a non-sedating barbiturate; Tonabersat (Upsher-Smith), which utilizes a novel mechanism of uncoupling of neuronal gap junctions; UCB0942 (UCB), a new pre- and post-synaptic inhibitor; VX-765 (Vertex), a selective inhibitor of interleukinconverting enzyme; YKP3089 (SK Life), which features a novel mechanism of action; 2-Deoxy-D-glucose (NeuroGenomeX), a glucose analog and glycolytic inhibitor; Ganaxolone (Marinus), a synthetic neurosteroid and GABA-A receptor modulator; Imepitoin, a low-affinity partial agonist at the benzodiazepine site of the GABA-A 
receptor; NAX 810-2 (NeuroAdjuvants), a galanin receptor 1 (GALR1) and GALR2 agonist; and Valnoctamide (Hebrew University), a valproic acid second-generation derivative. This list was obtained from Table 5 ("Pipeline of new drugs for epilepsy under development") of [67].

\section{Conclusion}

This article summarized some of the latest advances in the treatment of epilepsy. Clearly, much work remains, in particular in the identification and development of treatment modalities with an epileptogenic effect as well as disease-modifying properties. Sadly, while new AEDs with novel mechanisms of action and new molecular targets have been added to our pharmacologic armamentarium, their impact on treatment-resistant epilepsy has been very limited. Hopefully, future advances in research will change this landscape.

\section{Abbreviations}

AED, antiepileptic drug; AMPA, $\alpha$-amino-3-hydroxy-5methyl-4-isoxazole propionic acid; $\mathrm{AV}$, atrioventricular; BBB, blood-brain barrier; COX-2, cyclooxygenase-2; ESL, eslicarbazepine; EZG, ezogabine; FDA, US Food and Drug Administration; ICE, interleukin-1-beta-converting enzyme; IL, interleukin; LCM, lacosamide; LGS, LennoxGastaut syndrome; MRI, magnetic resonance imaging; mTOR, mammalian target of rapamycin; NSAID, nonsteroidal anti-inflammatory drug; PER, perampanel; RFN, rufinamide; SE, status epilepticus; TBI, traumatic brain injury; TLE, temporal lobe epilepsy; TSC, tuberous sclerosis complex; VGSC, voltage-gated sodium channel.

\section{Disclosures}

The authors declare that they have no disclosures.

\section{References}

I. Brodie MJ, Shorvon SD, Canger R, Halász P, Johannessen S, Thompson P, Wieser HG, Wolf P: Commission on European Affairs: appropriate standards of epilepsy care across Europe: ILAE. Epilepsia 1997, 38:1245-50.

2. Kwan P, Brodie MJ: Early identication of refractory epilepsy. N Engl J Med 2000, 342:314-19.

3. World Health Organization: Epilepsy Fact Sheet No. 999. World Health Organization (WHO); 2012. [http://www.who.int/mediacentre/ factsheets/fs999/en/index.html]

4. Fisher RS, van Emde Boas, Blume W, Elger C, Genton P, Lee P, Engel J Jr: Epileptic seizures and epilepsy: definitions proposed by the International League Against Epilepsy (ILAE) and the International Bureau for Epilepsy (IBE). Epilepsia 2005, 46:470-2.

5. Beyreuther BK, Freitag J, Heers C, Krebsfänger N, Scharfenecker U, Stöhr T: Lacosamide: a review of preclinical properties. CNS Drug Rev 2007, 13:21-42.

6. Halasz P, Kalviainen R, Mazurkiewicz-Beldzinska M, Rosenow F, Doty P, Hebert D, Sullivan T; SP755 Study Group: SP755 Study Group Adjunctive lacosamide for partial-onset seizures: Efficacy and safety results from a randomized controlled trial. Epilepsia 2009, 50:443-53.

\section{FlOOOPrime \\ RECOMMENDED}

7. Chung S, Sperling MR, Biton V, Krauss G, Hebert D, Rudd GD, Doty P; SP754 Study Group: Lacosamide as adjunctive therapy for partial onset seizures: a randomized controlled trial. Epilepsia 2010, 5 I:958-67.

\section{FlOOOPrime}

\section{RECOMMENDED}

8. Ramsay R, Sabharwal V, Khan F, Dave H: Safety and pharmacokinetics of IV loading dose of lacosamide in the ICU [abstract]. Presented at the $66^{\text {th }}$ Annual Meeting of the American Academy of Neurology: 26 April-3 May 2014; Philadelphia, PA.

9. Brodie MJ, Rosenfeld WE, Vazquez B, Sachdeo R, Perdomo C, Mann A, Arroyo S: Rufinamide for the adjunctive treatment of partial seizures in adults and adolescents: $A$ randomized placebocontrolled trial. Epilepsia 2009, 50:1899-909.

\section{FlOOOPrime}

\section{RECOMMENDED}

10. Elger CE, Stefan H, Mann A, Narurkar M, Sun Y, Perdomo C: A 24 week multicenter, randomized, double-blind, parallel group, dosage ranging study of rufinamide in adults and adolescents with inadequately controlled partial seizures. Epilepsy Res 2010, 88:255-63.

\section{FlOOOPrime}

RECOMMENDED

II. Glauser T, Kluger G, Sachdeo R, Krauss G, Perdomo C, Arroyo S: Rufinamide for generalized seizures associated with LennoxGastaut syndrome. Neurology 2008, 70:1950-8.

FlOOOPrime

RECOMMENDED

12. Brodie MJ, Lerche H, Gil-Nagel A, Elger C, Hall S, Shin P, Nohria V, Mansbach H; RESTORE 2 Study Group: RESTORE 2 Study Group. Efficacy and safety of adjunctive ezogabine (retigabine) in refractory partial epilepsy. Neurology 2010, 75:1817-24.

\section{FloOOPrime}

\section{RECOMMENDED}

13. Porter RJ, Partiot A, Sachdeo R, Nohria V, Alves WM; 205 Study Group: Randomized, multicenter, dose-ranging trial of retigabine for partial-onset seizures. Neurology 2007, 68:197-204.

14. French JA, Abou-Khalil BW, Leroy RF, Yacubian EM, Shin P, Hall S, Mansbach H, Nohria V; RESTORE I/Study 30I Investigators: On behalf of the RESTORE I/Study 30 I Investigators. Randomized, double-blind, placebo-controlled trial of ezogabine (retigabine) in partial epilepsy. Neurology 201 I, 3:1555-63.

15. FDA Drug Safety Communication: Anti-seizure drug Potiga (ezogabine) linked to retinal abnormalities and blue skin discoloration. U.S. Food and Drug Administration (FDA); 2013. [http://www.fda.gov/drugs/drugsafety/ucm349538.htm]

16. Parada A, Soares-da-Silva P: The novel anticonvulsant BIA2-093 inhibit its transmitter release during opening of voltagegated sodium channels: A comparison with carbamazepine and oxcarbazepine. Neurochem Int 2002, 40:435-40.

17. Bonifacio MJ, Sheridan RD, Parada A, Cunha RA, Patmore L, Soaresda-Silva P: Interaction of the novel anticonvulsant, BIA 2-093, with voltage-gated sodium channels: Comparison with carbamazepine. Epilepsia 200I, 42:600-8.

18. Almeida L, Soares-da-Silva P: Eslicarbazepine acetate (BIA 2-093) Neurotherapeutics 2007, 4:88-96.

19. Benes J, Parada A, Figueiredo AA, Alves PC, Freitas AP, Learmonth DA, Cunha RA, Garrett J, Soares-da-Silva P: Anticonvulsant and sodium channel-blocking properties of novel I0,II- dihydro$5 \mathrm{H}$ - dibenz $[\mathrm{b}, \mathrm{f}]$ azepine-5-carboxamide derivatives. J Med Chem 1999, 42:2582-7. 
20. Ben-Menachem E, Gabbai AA, Hufnagel A, Maia J, Almeida L, Soaresda-Silva P: Eslicarbazepine acetate as adjunctive therapy in adult patients with partial epilepsy. Epilepsy Res 2010, 89:278-85.

\section{FlOOOPrime
RECOMMENDED}

21. Hufnagel A, Ben-Menachem E, Gabbai AA, Falcão A, Almeida L, Soares-da-Silva $P$ : Long-term safety and efficacy of eslicarbazepine acetate as adjunctive therapy in the treatment of partial-onset seizures in adults with epilepsy: results of a I-year open-label extension study. Epilepsy Res 2013, 103:262-9.

\section{FlOOOPrime}

\section{RECOMMENDED}

22. French JA, Krauss GL, Steinhoff BJ, Squillacote D, Yang H, Kumar D, Laurenza $A$ : Evaluation of adjunctive perampanel in patients with refractory partial-onset seizures: results of randomized global phase III study 305. Epilepsia 2013, 54:1 17-25.

\section{FIOOOPRime
RECOMMENDED}

23. French JA, Krauss GL, Biton V, Squillacote $D$, Yang $H$, Laurenza $A$, Kumar D, Rogawski MA: Adjunctive perampanel for refractory partial-onset seizures: randomized phase III study 304. Neurology 2012, 79:589-96.

\section{FlOOOPrime}

\section{RECOMMENDED}

24. News Release: Laser ablation surgery shows better cognitive results for people with epilepsy. [http://news.emory.edu/stories/ 2013/I2/better_memory_with_laser_epilepsy_surgery/index.html]

25. News Release: Laser Ablation Promising in Patients with Epilepsy. [http://www.medscape.com/viewarticle/817498]

26. FDA News Release: FDA approves medical device to treat epilepsy. [http://www.fda.gov/newsevents/newsroom/pressannoun cements/ucm37504I.htm]

27. Morrell MJ: RNS System in Epilepsy Study Group. Neurology 20II, 77: 1295-304.

\section{FlOOOPrime}

RECOMMENDED

28. Lagae L, Buyse G, Ceulemans B, Claeys P, Dedeurwaerdere S, De Meirleir L, Hauman R, Janssen A, Schmedding E, Verhelst H, Vonck K: Anti-epileptogenesis research: the clinical relevance. Acta Neurol Belg 2003, 103:78-82.

29. Löscher W, Brandt C: Prevention or modification of epileptogenesis after brain insults: experimental approaches and translational research. Pharmacol Rev 2010, 62:668-700.

30. Pitkänen $A$, Lukasiuk $K$ : Mechanisms of epileptogenesis and potential treatment targets. Lancet Neurol 20II, 10:173-86.

31. Löscher W: Strategies for antiepileptogenesis, $4^{\text {th }}$ edition. New York: Oxford University Press; 2012

32. Pitkänen A, Sutula TP: Is epilepsy a progressive disorder? Prospects for new therapeutic approaches in temporal lobe epilepsy. Lancet Neurol 2002, I:I73-81.

33. Herman ST: Epilepsy after brain insult: targeting epileptogenesis. Neurology 2002, 59(Suppl 5):S2I-6.

34. Temkin NR: Preventing and treating posttraumatic seizures: the human experience. Epilepsia 2009, 50(Suppl 2):10-13

35. Zeng LH, Rensing NR, Wong M: The mammalian target of rapamycin signaling pathway mediates epileptogenesis in a model of temporal lobe epilepsy. J Neurosci 2009, 29:6964-72.

\section{FlOOOPrime
RECOMMENDED}

36. Watanabe R, Wei L, Huang J: mTOR signaling, function, novel inhibitors, and therapeutic targets. J Nucl Med 20I I, 52:497-500.

37. Jones RG, Thompson CB: Tumor suppressors and cell metabolism: a recipe for cancer growth. Genes and Dev 2009, 23:537-48.

38. Sarbassov DD, Ali SM, Sabatini DM: Growing roles for the $\mathbf{m T O R}$ pathway. Curr Opin Cell Biol 2005, 17:596-603.
39. Meng XF, Yu JT, Song JH, Chi S, Tan L: Role of the mTOR signaling pathway in epilepsy. J Neurol Sci 2013, 15:4-15.

40. Smalley SL: Autism and tuberous sclerosis. J Autism Dev Disord 1998, 28: 407-I4.

4I. Moavero R, Coniglio A, Garaci F, Curatolo P: Is mTOR inhibition a systemic treatment for tuberous sclerosis? Ital J Pediatr 2013, 39:57.

FIOOOPRime
RECOMMENDED

42. Kwiatkowski DJ: Tuberous Sclerosis: from Tubers to $\mathbf{m T O R}$. Ann Hum Genet 2003, 67:87-96.

43. Zeng LH, Xu L, Gutmann DH, Wong M: Rapamycin prevents epilepsy in a mouse model of tuberous sclerosis complex. Ann Neurol 2008, 39:444-53.

\section{FlOOOPrime}

RECOMMENDED

44. Wiederrecht GJ, Sabers CJ, Brunn GJ, Martin MM, Dumont FJ, Abraham RT: Mechanism of action of rapamycin: new insights into the regulation of GI-phase progression in eukaryotic cells. Prog Cell Cycle Res 1995, I:53-7I.

45. Lieberthal W, Levine JS: The Role of the Mammalian Target Of Rapamycin (mTOR) in Renal Disease. J Am Soc Nephrol 2009, 20:2493-502.

46. Vezzani A, French J, Bartfai T, Baram TZ: The role of inflammation in epilepsy. Nat Rev Neurol 201 I, 7:31-40.

\section{FlOOOPrime} RECOMMENDED

47. Vezzani A, Friedman A, Dingledine RJ: The role of inflammation in epileptogenesis. Neuropharmacology 2012:I-9.

48. Oby E, Janigro D: The blood-brain barrier and epilepsy. Epilepsia 2006, 47: 176I-74.

49. Viviani B, Gardoni F, Marinovich M: Cytokines and neuronal ion channels in health and disease. Int Rev Neurobiol 2007, 82:247-63.

50. Wetherington J, Serrano G, Dingledine R: Astrocytes in the epileptic brain. Neuron 2008, 58:168-78.

5I. Friedman A, Kaufer D, Heinemann U: Blood-brain barrier breakdown-inducing astrocytic transformation: novel targets for the prevention of epilepsy. Epilepsy Res 2009, 85: I42.

\section{FlOOOPrime
RECOMMENDED}

52. Xu D, Miller SD, Koh S: Immune mechanisms in epileptogenesis. Front Cell Neuroscience 2013, 7:195

53. Choi J, Nordli DR, Koh S: Cellular injury and neuroinflammation in children with chronic intractable epilepsy. J Neuroinflammation 2009, 6:38.

\section{FlOOOPrime
RECOMMENDED}

54. Friedman A, Dingledine R: Molecular cascades that mediate the influence of inflammation on epilepsy. Epilepsia 20II, 52 (Suppl. 3):33-9.

55. Shafiq N, Malhotra S, Pandhi P: Anticonvulsant action of celecoxib (alone and in combination with sub-threshold dose of phenytoin) in electroshock induced convulsion. Methods Find Exp Clin Pharmacol 2003, 25:87-90.

56. Dhir A, Naidu PS, Kulkarni SK: Effect of naproxen, a non-selective cyclo-oxygenase inhibitor, on pentylenetetrazol induced kindling in mice. Clin Exp Pharmacol Physiol 2005, 32:574-84.

57. Dhir A, Naidu PS, Kulkarni SK: Neuroprotective effect of nimesulide, a preferential COX-2 inhibitor, against pentylenetetrazole (PTZ)-induced chemical kindling and associated biochemical parameters in mice. Seizure 2007, 16:691-7.

FlOOOPrime RECOMMENDED

58. Vezzani A, Balosso S, Maroso M, Zardoni D, Noé F, Ravizza T: ICE/ caspase I inhibitors and IL-I beta receptor antagonists as 
potential therapeutics in epilepsy. Curr Opin Investig Drugs 2010 , II:43-50.

59. Jung KH, Chu K, Lee ST, Kim J, Sinn DI, Kim JM, Park DK, Lee JJ, Kim SU, Kim M, Lee SK, Roh JK: Cyclooxygenase-2 inhibitor, celecoxib, inhibits the altered hippocampal neurogenesis with attenuation of spontaneous recurrent seizures following pilocarpine-induced status epilepticus. Neurobiol Dis 2006, 23: 237-46.

\section{FlOOOPrime RECOMMENDED}

60. Polascheck N, Bankstahl M, Löscher W: The COX-2 inhibitor parecoxib is neuroprotective but not antiepileptogenic in the pilocarpine model of temporal lobe epilepsy. Exp Neurol 2010, 224:219-33

\section{FlOOOPrime}

\section{RECOMMENDED}

61. Zibell G, Unkrüer B, Pekcec A, Hartz A, Bauer B, Miller DS, Potschka H: Prevention of seizure-induced up-regulation of endothelial P-glycoprotein by COX-2 inhibition. Neuropharmacology 2009, 56:849-55.

\section{FlOOOPrime} RECOMMENDED

62. Henshall DC, Clark RS, Adelson PD, Chen M, Watkins SC, Simon RP: Alterations in bcl-2 and caspase gene family protein expression in human temporal lobe epilepsy. Neurology 2000, 55:250-7.

63. Maroso M, Balosso S, Ravizza T, lori V, Wright Cl, French J, Vezzani A: Interleukin-1 $\beta$ Biosynthesis Inhibition Reduces Acute Seizures and Drug Resistant Chronic Epileptic Activity in Mice. Neurotherapeutics 20II, 8:304-15.

\section{FlOOOPrime}

\section{RECOMMENDED}

64. Kälviäinen $R$, Salmenperä $T$, Partanen $K$, Vainio $P$, Riekkinen $P$, Pitkänen $A$ : Recurrent seizures may cause hippocampal damage in temporal lobe epilepsy. Neurology 1998, 50:1377-82.

65. Meldrum BS, Bruton C]: Epilepsy. In Greenfield's Neuropathology. 5th edition. Edited by Adams JH, Duchen LW. New York: Oxford University Press; 1992:1246-83.

66. Narkilahti S, Jutila L, Alafuzoff I, Karkola K, Paljärvi L, Immonen A, Vapalahti M, Mervaala E, Kälviäinen R, Pitkänen A: Increased expression of caspase 2 in experimental and human temporal lobe epilepsy. Neuromolecular Med 2007, 9:129-44.

FlOOOPrime

67. Reddy DS: Role of hormones and neurosteroids in epileptogeneisis. Front Cell Neuroscience 2013, 7:I-20.

68. Harrison NL, Simmonds MA: Modulation of the GABA receptor complex by a steroid anaesthetic. Brain Res 1984, 323:287-92.

69. Harrison NL, Majewska MD, Harrington JW, Barker JL: Structure activity relationships for steroid interactions with the $\gamma$-aminobutyric acidA receptor complex. J Pharmacol Exp Ther 1987, 24I:346-53.

70. Majewska MD, Harrison NL, Schwartz RD, Barker JL, Paul SM: Steroid hormone metabolites are barbiturate-like modulators of the GABA receptor. Science 1986, 232:1004-7.

7I. Gee KW, Bolger MB, Brinton RE, Coirini H, McEwen BS: Steroid modulation of the chloride ionophore in rat brain: structureactivity requirements, regional dependence and mechanism of action. J Pharmacol Exp Ther 1988, 246:803-12.

72. Purdy RH, Morrow Al, Blinn JR, Paul SM: Synthesis, metabolism, and pharmacological activity of $3 \alpha$-hydroxy steroids which potentiate GABA-receptor-mediated chloride ion uptake in rat cerebral cortical synaptoneurosomes. J Med Chem 1990, 33:1572-8I.

73. Hosie AM, Wilkins ME, Smart TG: Neurosteroid binding sites on GABA-A receptors. Pharmacol Ther 2007, I 16:7-19.

74. Hosie AM, Clarke L, da Silva H, Smart TG: Conserved site for neurosteroid modulation of GABA-A receptors. Neuropharmacology 2009, 56:149-54.

75. Reddy DS, Gangisetty O, Brival S: Disease-modifying activity of progesterone in the hippocampus kindling model of epileptogenesis. Neuropharmacology 2010, 59:573-81.

\section{FlOOOPrime}

\section{RECOMMENDED}

76. Reddy DS, Ramanathan G: Finasteride inhibits the diseasemodifying activity of progesterone in the hippocampus kindling model of epileptogenesis. Epilepsy Behav 2012, 25:92-7.

\section{FlOOPrime}

\section{FEOPMime}

77. Bialer M, Johannessen SI, Levy RH, Perucca E, Tomson T, White HS: Progress report on new antiepileptic drugs: $A$ summary of the Eleventh Eilat Conference (EILAT XI). Epilepsy Res 20I3, 103:2-30.

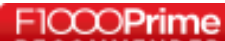

